\title{
Management of Severe Acute Pancreatitis
}

\author{
Peter J. Lee, $M B C h B^{1}$ \\ Georgios I. Papachristou, MD, PhD ${ }^{2, *}$
}

\author{
Address \\ ${ }^{1}$ Division of Gastroenterology and Hepatology, Department of Medicine, Hospital \\ of the University of Pennsylvania, Philadelphia, PA, USA \\ ${ }^{*}, 2$ Division of Gastroenterology and Hepatology, Department of Medicine, Ohio \\ State University Wexner Medical Center, 410 W 10th Street, 2nd floor, Columbus, \\ $\mathrm{OH}, 43210$, USA \\ Email: georgios.papachristou@osumc.edu
}

Published online: 19 November 2020

(C) Springer Science+Business Media, LLC, part of Springer Nature 2020

This article is part of the Topical Collection on Pancreas

Keywords Severe pancreatitis $\cdot$ Organ failure $\cdot$ Inflammatory cytokines $\cdot$ Necrotizing pancreatitis

\begin{abstract}
Purpose of review There have been significant advancements in different aspects of management of severe acute pancreatitis (SAP). Our review of the most recent literature focuses on severity prediction, fluid resuscitation, analgesic administration, nutrition, and endoscopic intervention for SAP and its extra-pancreatic complications.

Recent findings Recent studies on serum cytokines for the prediction of SAP have shown superior prognostic performance when compared with conventional laboratory tests and clinical scoring systems. In patients with established SAP and vascular leak syndrome, intravenous fluids should be administered with caution to prevent intra-abdominal hypertension and volume overload. Endoscopic retrograde cholangiopancreatography improves outcomes only in AP patients with suspected cholangitis. Early enteral tubefeeding does not appear to be superior to on-demand oral feeding. Abdominal compartment syndrome is a highly lethal complication of SAP that requires percutaneous drainage or decompressive laparotomy. Endoscopic transmural drainage followed by necrosectomy (i.e., "step-up approach") is the treatment strategy of choice in patients with symptomatic or infected walled-off pancreatic necrosis.

Summary SAP is a complex clinical syndrome associated with a high mortality rate. Early prediction of SAP remains challenging due to the limited accuracy of the available prediction tools. Early fluid resuscitation, organ support, enteral nutrition, and prevention of/or prompt recognition of abdominal compartment syndrome remain cornerstones of its management. A step-up, minimally invasive drainage/debridement is the preferred approach for patients with infected pancreatic necrosis.
\end{abstract}




\section{Introduction}

Acute pancreatitis (AP) is an acute inflammatory disease that results from pancreatic injury via various mechanisms $[1 \bullet \bullet]$. Its incidence is increasing worldwide, and it continues to be among the top causes of GI-related hospitalizations in the USA [2]. Several key pathophysiologic mechanisms of organ injury in AP have been recently identified $[1 \bullet \bullet]$. These include intra- and peripancreatic fat lipolysis, exaggerated immune response, and microvascular dysfunction leading to vascular leak syndrome $[1 \bullet \bullet]$. AP- and ischemiaconditioned mesenteric lymph is being explored as another potential mediator of severe acute pancreatitis (SAP) [3-6]. Approximately half of all AP patients develop a systemic inflammatory response, which can then progress to organ failure and even death $[7,8]$. Two major determinants of morbidity and mortality include pancreatic necrosis and presence of end-organ injury, respectively [9]. SAP, defined by presence of persisting organ failure $[9,10 \bullet]$, represents a relatively small subgroup of all AP patients (10-20\%), in whom the risk of death is particularly high. The majority of mortality occurs within the first 2 weeks of presentation, making early prediction an important part of management of SAP [11•]. Pancreatic necrosis often accompanies endorgan failure; however, development of pancreatic necrosis in the absence of organ failure does not lead to increased mortality [12].

Early prediction of SAP continues to be limited by lack of accurate prognostic tools [13]. Measurement of serum cytokines such as IL- 6 , IL-8, angiopoietin-2, and resistin appears to predict SAP more accurately than laboratory tests and clinical scoring systems, but head-to-head comparison studies are lacking and cytokine measurements are not available in clinical practice [14-16]. Recently there have been several advancements in defining the timing and type of endoscopic therapy in AP patients with infected walled-off pancreatic necrosis and the role of endoscopic biliary decompression in biliary AP $[17 \bullet \bullet]$. There continues to be paucity of data on the optimal strategies for intravenous fluid resuscitation, administration of analgesia, and management of intra-abdominal hypertension. This review will summarize the most recent literature covering the above aspects of SAP management.

\section{Definition}

What constitutes SAP had been a subject of debate until recently [10•]. In the past, presence of acute fluid collections, and necrosis independently qualified subjects as having severe pancreatitis until a new definition of severe pancreatitis was proposed by the Revised Atlanta Classification experts [9]. The distinguishing feature of SAP from mild and moderately severe pancreatitis is presence of persistent organ failure (organ failure persisting for $48 \mathrm{~h}$ or longer; see Table 1). Recent data indicates that in the absence of organ failure, prognosis of AP patients is favorable even in the presence of necrosis and fluid collections [18]. Before the advent of minimally invasive drainage techniques, patients with infected pancreatic necrosis carried a significant mortality even in the absence of persistent organ failure [19], but its prognosis has improved largely in the recent years $[11 \bullet 17 \bullet \bullet]$. Therefore, while infected walled-off pancreatic necrosis is an indication for intervention, it is not classified as SAP by the Revised Atlanta Classification.

\section{Pathophysiology}

Pathogenesis of organ failure in AP is still not clearly delineated [6]. However, several hypothesized mechanisms have recently been developed: 
Table 1. Revised Atlanta Classification

\begin{tabular}{|c|c|c|c|}
\hline & Mild & Moderately severe & Severe \\
\hline \multirow[t]{2}{*}{ Determinants } & $\begin{array}{l}\text { No acute fluid or } \\
\text { necrotic } \\
\text { collections, } \\
\text { No exacerbation } \\
\text { of a comorbid } \\
\text { condition, } \\
\text { No organ failure }\end{array}$ & $\begin{array}{l}\text { Transient organ failure } \\
\text { (organ failure lasting } 24 \\
\text { hours or less) } \\
\text { and/or } \\
\text { Presence of fluid or necrotic } \\
\text { collection } \\
\text { and/or } \\
\text { Exacerbation of a comorbid } \\
\text { condition }\end{array}$ & $\begin{array}{l}\text { Presence of } \\
\text { persistent organ } \\
\text { failure* }\end{array}$ \\
\hline & $\begin{array}{l}\text { Type of local } \\
\text { complication }\end{array}$ & $<4$ weeks & $>/=4$ weeks \\
\hline \multirow[t]{2}{*}{$\begin{array}{l}\text { Local } \\
\text { complications }\end{array}$} & $\begin{array}{l}\text { Fluid collection } \\
\text { without necrosis }\end{array}$ & Acute fluid collection & Pseudocyst \\
\hline & $\begin{array}{l}\text { Fluid collection } \\
\text { with necrosis }\end{array}$ & Acute necrotic collection & $\begin{array}{l}\text { Walled off } \\
\text { pancreatic necrosis }\end{array}$ \\
\hline
\end{tabular}

\section{Adipose tissue lipolysis}

Obesity has long been identified as a risk factor for SAP [20]. Recent evidence from animal models has suggested that unsaturated free fatty acids produced from periand intra-pancreatic parenchymal fat upon lipase mediated lipolysis, are toxic and lead to mitochondrial dysfunction in end-organs $[5,21,22 \bullet]$. This hypothesis is supported by clinical studies showing that increased visceral adiposity is associated with higher risk of organ failure [23]. In contrast, pancreatic parenchymal fibrosis, which limits the lipolytic flux, appears to protect against SAP [24].

\section{Severe innate immune response}

Exaggerated immune response to local parenchymal injury has long been observed to precede organ dysfunction in AP. For example, pro-inflammatory cytokines are markedly elevated early in the disease course. These include interleukin 6 (IL-6), IL8, monocyte chemoattractant protein-1 (MCP-1), and TNF- $\alpha$ [6]. Based on the above findings, a randomized controlled trial (RCT) was recently initiated assessing a TNF- $\alpha$ inhibitor as a potential treatment option in AP (NCT03684278). Supporting the central role of exaggerating innate immune response in mediating SAP, a recently completed RCT showed that administration of COX-2 inhibitors in AP subjects reduced the incidence of SAP by an absolute difference of $19 \%$ compared to placebo [25]. Additionally, disease-associated molecular patterns (DAMPs) have been found to be elevated in AP and their levels appear to predict SAP. DAMPs are intra-cellular contents that are released upon cell death and can cause a potent immune response [26]. This suggests the amount of DAMPs released may also have a key role in exaggerated innate immune response.

Systemic microvascular dysfunction is one of the pathways leading to SAP. Vascular leak results in marked third space fluid sequestration and may lead 
to abdominal compartment syndrome similar to other critical illnesses [27]. Endothelial integrity, maintained by the Tie 2 pathway under physiologic conditions, is markedly downregulated in SAP and sepsis [28]. Angiopoietin-2 is a paracrine peptide that destabilizes endothelial cells and increases vascular permeability via inhibition of the Tie2 pathway. Angiopoietin-2 levels are increased in patients with SAP and predict SAP with high accuracy $[14,29]$. Nonetheless, a therapeutic agent targeting microvascular dysfunction has not yet been tested in AP; such mechanistic studies are underway for sepsis models [30].

\section{Mesenteric lymph}

\section{Management}

There is preliminary evidence supporting that ischemia-conditioned and AP-conditioned mesenteric lymph mediates cardiac dysfunction. In a recent animal study in rats, cardiac output, contractility, and relaxability decreased significantly upon infusion of mesenteric lymph conditioned by AP into rats [31•]. Cardiac dysfunction could then be reversed upon external drainage and thoracic duct ligation [31•]. Specific mediators of organ dysfunction in the mesenteric lymph have not yet been elucidated. Ongoing studies are evaluating the impact of thoracic duct diversion in other disease models, such as sepsis. This is a novel research area in the field of SAP; once the mechanism is delineated, it will have a potential impact in the management of SAP.

\section{Severity prediction}

The majority of organ dysfunction in AP occurs within the first week of presentation and its development can be rapid [11•]. For appropriate assignment of care, organ support, and future therapeutic studies, prediction of SAP has been a major focus of many studies [32, 33]. Over a dozen laboratory tests and clinical scoring systems have been proposed; however, their predictive accuracies have only been suboptimal for meaningful clinical application $[13,32,34]$. Serum cytokine measurements and machine learning may lead to developing tools with higher predictive accuracies [35-37]. Promising cytokines as candidates for accurate prediction of SAP include angiopoietin-2, resistin, and interleukin-6 [36-38] (Table 2). With the development of point of care assays for interleukin6, its integration for use in SAP may be possible in the near future [38]. However, further studies are needed to explore the optimal cytokine utility for AP prediction in clinical practice.

Most widely used, routinely available laboratory tests and clinical scores include hematocrit, BUN, systemic inflammatory response syndrome (SIRS), and Bedside Index of Severity of Acute Pancreatitis (BISAP) [39, 40]. Hemoconcentration, BUN elevation greater than $20 \mathrm{mg} / \mathrm{dL}$ with an upward trend, SIRS score of 2 or more, and BISAP score of 3 or more are all validated predictors of AP severity, but with only modest sensitivity and specificity [13]. Our clinical practice is to calculate the SIRS score daily, which is easy to measure requiring only vital signs and white blood cell count; the score ranges from 0 to 4 . We closely monitor SIRS positive patients, especially with a score of 3 or 4 , for signs of organ failure. 
Table 2. List of cytokines and their accuracy in predicting severe pancreatitis or mortality

\begin{tabular}{|c|c|c|}
\hline Name of cytokine & Function & AUC \\
\hline $\begin{array}{l}\text { Interleukin-1 } \beta \\
\quad(\mathrm{IL}-1 \beta)\end{array}$ & $\begin{array}{l}\text { Pro-inflammatory cytokine: stimulates macrophages, causes lymphocyte maturation; } \\
\text { induces acute phase protein production; facilitates leukocyte trafficking }\end{array}$ & $74-82 \%$ \\
\hline $\begin{array}{l}\text { Interleukin-6 } \\
\quad(\mathrm{IL}-6)\end{array}$ & $\begin{array}{l}\text { Pro-inflammatory cytokine: regulates T lymphocyte activation and differentiation; } \\
\text { induces acute phase protein production; facilitates neutrophil trafficking }\end{array}$ & $75-88 \%$ \\
\hline $\begin{array}{l}\text { Interleukein-8 } \\
\quad(\mathrm{IL}-8)\end{array}$ & Pro-inflammatory cytokine with function similar to IL-6 & $73-76 \%$ \\
\hline $\begin{array}{c}\text { Tumor Necrosis } \\
\text { Factor- } \alpha \\
\text { (TNF- } \alpha)\end{array}$ & $\begin{array}{l}\text { Pro-inflammatory cytokine: induces acute phase protein production; activates } \\
\text { neutrophils and macrophages }\end{array}$ & $81 \%$ \\
\hline Angiopoeitin-2 & Autocrine peptide regulator of vascular permeability & $74-81 \%$ \\
\hline Resistin & Adipokine: induces production of IL-1 $\beta$, IL- 6 , and TNF- $\alpha$ & $76-80 \%$ \\
\hline Visfatin & Adipokine: induces production of IL-1 $\beta$, IL- 6 , and TNF- $\alpha$ & $74 \%$ \\
\hline $\begin{array}{l}\text { Monocyte } \\
\text { chemotactic } \\
\text { protein-1 } \\
(\mathrm{MCP}-1)\end{array}$ & $\begin{array}{l}\text { Chemokine secreted early in the disease course; induces recruitment of monocytes, } \\
\text { lymphocytes, mast cells, and eosinophils }\end{array}$ & $88 \%$ \\
\hline
\end{tabular}

Aggressive fluid resuscitation for prevention of necrotizing and severe pancreatitis has long been regarded as the cornerstone of early management of AP [41], but controversy persists in matters of the type, rate, and duration of fluid administration [42]. There has been promising evidence to support the role of early aggressive fluid resuscitation with Lactated Ringers in mild AP [43]; however, in subjects with predicted SAP, prolonged aggressive volume administration may be harmful [44]. Specifically, in SAP patients with systemic vascular leak syndrome, aggressive fluid resuscitation may increase thirdspacing and intra-abdominal pressure, which can lead to the development of abdominal compartment syndrome and respiratory failure [44-46]. Thus, after initiation of fluid therapy, endpoints such as urine output, mean arterial pressure, oxygen saturation with respiratory rate, and intra-abdominal pressure should be closely monitored early in the disease course. Persistent aggressive fluid administration should be avoided if these endpoints suggest impending volume overload (i.e., decreasing saturation with tachypnea and increasing intra-abdominal pressure) without improvement in end-organ perfusion (i.e., persistent low urine output and/or hypotension).

Experts advocate to assess patients' fluid responsiveness before administering fluid therapy and then monitor intra-abdominal pressure [47]. The fluid resuscitation strategy should be goal-directed and determined by patient's fluid responsiveness, time elapsed since disease onset (benefits of aggressive fluid resuscitation may be marginal beyond $24 \mathrm{~h}$ after onset of disease [48, 49]), and patient's propensity for fluid sequestration and risk for abdominal compartment syndrome. Our clinical practice is to initiate early fluid resuscitation as soon as the AP diagnosis is established in the Emergency Department by 
administering 1-2 L of Lactated Ringers bolus. Subsequently, we recommend administration of Lactated Ringers at a rate of $3 \mathrm{cc} / \mathrm{kg} / \mathrm{h}(\sim 200 \mathrm{cc} / \mathrm{h}$ for a $70-\mathrm{kg}$ patient) and reassess patient's fluid responsiveness at 12 and $24 \mathrm{~h}$.

The gut barrier dysfunction is a common and well-recognized phenomenon in SAP [50]. Enteral feeding has a clear benefit in reducing morbidity and mortality over parenteral nutrition [51]. However, it is controversial whether early nutrition through a nasoenteric feeding tube is better than "on-demand" oral feeding. In a large RCT in predicted severe pancreatitis patients, early enteral tube-feeding did not appear to confer significant

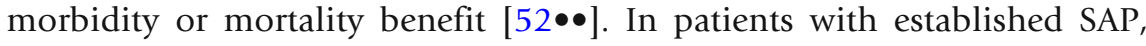
however, there is insufficient evidence for or against early enteral feeding [53]. Additionally, the comparative effectiveness of the route of enteral nutrition and specifically nasogastric versus nasojejunal feeding needs to be investigated further [54]. Based on the available evidence, we recommend offering an oral diet (a low fat solid diet) and assessing patients' tolerance. In intubated patients, enteral feeding should be pursued with a nasogastric feeding tube unless there is evidence of gastric outlet obstruction from peri/pancreatic edema and fluid, in which case endoscopic placement of nasojejunal feeding tube can be pursued. In most tertiary care centers, there are non-invasive tools that guide enteral tube placement into the post-pyloric location. Where this tool is available, nasoduodenal tube placement is also acceptable.

Pain in subjects with SAP is typically managed with opioids in the USA; however, there are significant geographical variations in AP pain management worldwide, which highlights the need for additional evidence in this domain [55]. In animals with $\mathrm{AP}$, morphine worsens the severity of $\mathrm{AP}$ and inhibits pancreatic regeneration [56•]; also codeine, a different opioid, has been implicated as a risk factor for AP among patients who undergo cholecystectomy [57]. Postulated mechanisms include increased bacterial translocation due to intestinal dysmotility, increased sphincter of Oddi pressure, and delay in regenerative immune response [56•]. Nevertheless, these hypotheses have not been tested in clinical studies.

Non-steroidal anti-inflammatory drugs (NSAIDs), such as COX-2 inhibitors, have recently shown encouraging results in prevention of SAP. However, due to their propensity for nephrotoxicity, they may not be a feasible option in patients with established SAP, many of whom are in renal failure [25]. Recognizing this limitation, researchers have investigated the benefit of administering epidural analgesia containing non-opioid agents. In patients with SAP requiring intensive care unit, there is early evidence for mortality benefit [58•]. A randomized clinical trial is underway to investigate the benefits of thoracic epidural analgesia in AP patients requiring intensive care unit admission [59]. In our clinical practice, opioids remain the most effective short-term analgesic agents for alleviation of pain in SAP; however, they should be administered judiciously, especially in the presence of ileus. 


\section{Role of ERCP in biliary pancreatitis}

Patients with predicted SAP resulting from gallstones commonly develop abnormal liver function tests and jaundice, due to the extensive pancreatic head edema that causes obstruction at the intrapancreatic portion of the common bile duct and/or co-existing choledocholithiasis. In this subgroup of patients, biliary decompression with biliary sphincterotomy had been postulated to confer morbidity and mortality benefits. However, in a recent randomized clinical trial, early decompression of the bile duct in this population did not reduce the composite endpoint of mortality or major complications within 6 months [60]. As such, our clinical practice is to reserve ERCP for AP patients of biliary etiology with evidence of choledocholithiasis on imaging or clinical suspicion of cholangitis with prompt biliary drainage within 24 to $48 \mathrm{~h}$.

Due to extensive intra-abdominal edema that occurs from fluid extravasation secondary to third-spacing and potential aggressive fluid resuscitation, intra-abdominal hypertension (IAH) is relatively common in SAP patients [61]. IAH is defined by intra-abdominal pressure higher than $12 \mathrm{mmHg}$ and is a precursor to intra-abdominal compartment syndrome (ACS; > $20 \mathrm{mmHg}$ ), which carries a poor prognosis [62]. It is unclear whether IAH is an epiphenomenon or a distinct entity that requires prompt recognition and treatment. If ACS ensues, decompressive laparotomy should be considered urgently for prevention of worsening end-organ failure. Percutaneous drainage represents an alternative decompressive modality in ACS when feasible [45]. Further studies are needed to clarify the type and timing of decompressive techniques that can lower intra-abdominal pressure and their impact on morbidity and mortality in SAP. Our clinical practice is to measure intra-bladder pressures in AP patients in the ICU with respiratory failure when they develop increased ventilator requirements. When IAH is confirmed, we then proceed with cross-sectional imaging to assess for any drainable large pancreatic fluid collections.

Role of endoscopic cystenterostomy with/without necrosectomy

Necrotizing pancreatitis accompanies commonly SAP. In patients with SAP and coexisting acute necrotic collections or walled-off pancreatic necrosis, drainage with/without necrosectomy is indicated in several instances. The most rigorously studied population is those with infected walled-off pancreatic necrosis $[17 \bullet \bullet]$. In this population, drainage should be considered when the medical condition does not improve with maximum medical therapy. A "step-up" to minimally invasive necrosectomy should be considered in patients in whom drainage does not lead to a significant improvement with $72 \mathrm{~h}$. We recommend percutaneous drainage as the modality of choice when the necrotic collection is less than 4 weeks old, whereas, for walled-off pancreatic necrosis (mature necrotic collections older than 4 weeks), transmural endoscopic drainage followed by necrosectomy appears to be superior to percutaneous drainage with video-assisted retroperitoneal debridement based on lower rates of

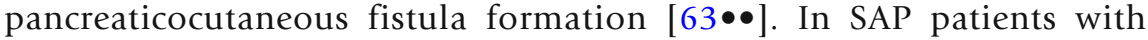




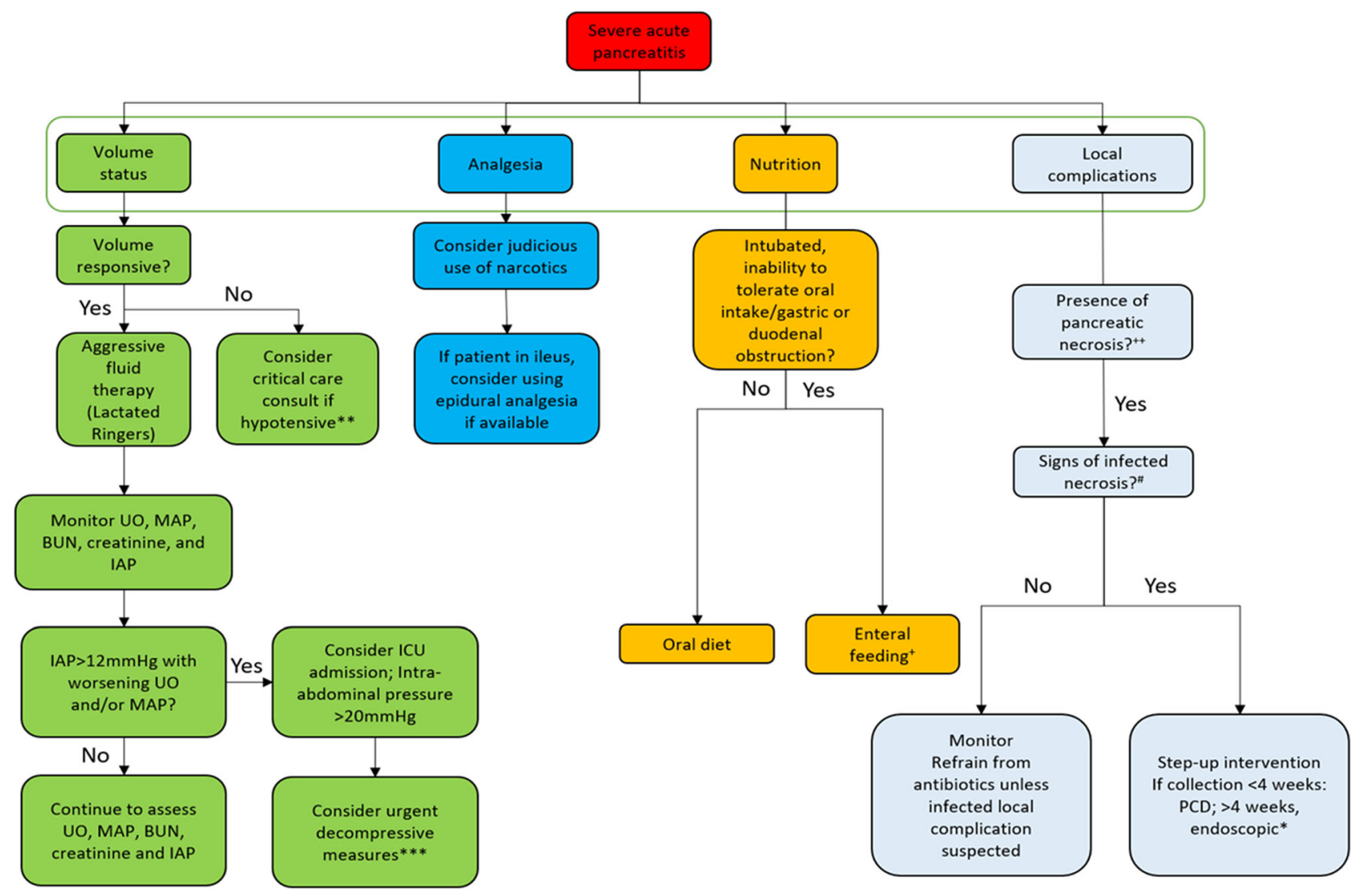

Fig. 1. Management algorithm of severe acute pancreatitis according to separate domains. U0, urine output; MAP, mean arterial pressure; BUN, blood urea nitrogen; IAP, intra-abdominal pressure; ICU, intensive care unit; PCD, percutaneous drainage. ${ }^{+}$Nasojejunal route in patients with gastric or duodenal obstruction; ${ }^{++}$presence of necrosis is best established with a contrastenhanced cross-sectional imaging; "\# signs of infected necrosis include gas within a necrotic collection, or worsening organ failure in a patient with necrotic collection despite maximum medical therapy in the intensive care unit, or new onset fevers in patients with established necrotic collection; * endoscopic step-up intervention: endoscopic ultrasound guided transmural drainage, followed by endoscopic necrosectomy if there is no clinical improvement in $72 \mathrm{~h}$; **in hypotensive SAP patients who are not fluid responsive, intensive care unit admission needs to be considered to prevent volume overload; ${ }^{* *}$ decompressive measures include decompressive laparotomy or percutaneous drain placement.

symptomatic, sterile necrotic collections, data on the optimal management strategy is sparse [40].

\section{Conclusions}

SAP is defined as AP complicated by persisting organ failure. It is a complex clinical syndrome, which is challenging to manage and carries a significant mortality. There have been significant advancements in understanding the underlying pathophysiology of SAP, including intra- and extra-pancreatic fat lipolysis, severe innate immune response, and microvascular dysfunction. However, therapeutic pharmaceutical targets have not yet been identified for 
clinical trials, with the exception of TNF- $\alpha$ and COX-2 inhibition. Serum cytokine measurements appear promising for early accurate prediction of SAP, but they are not readily available in clinical practice. In addition to supportive therapy for end-organs, management strategies should address 4 main domains of SAP including (1) volume status: with fluid resuscitation guided by assessment of fluid responsiveness, intra-abdominal pressure, and markers of intravascular volume status; (2) analgesia with administration of non-steroidal antiinflammatory drugs, opioids, or epidural analgesia in expert centers; (3) gutbarrier dysfunction: with nutritional support via on-demand oral or enteral feeding; and (4) infected necrotic collections: with minimally invasive drainage approaches and necrosectomy in a step-up manner (Fig. 1).

\section{Compliance with ethical standards}

\section{Conflict of interest}

Peter J. Lee declares that he has no conflict of interest. Georgios I. Papachristou declares that he has no conflict of interest.

\section{References and Recommended Reading}

Papers of particular interest, published recently, have been highlighted as:

- Of importance

$\bullet$ Of major importance

1.• Lee PJ, Papachristou GI. New insights into acute pancreatitis. Nat Rev Gastroenterol Hepatol. England. 2019;

This review summarizes recent evidence for mechanisms of acute pancreaittis.

2. Petrov MS, Yadav D. Global epidemiology and holistic prevention of pancreatitis. Nat Rev Gastroenterol Hepatol. England. 2018;16(3):175-84.

3. Navina S, Acharya C, DeLany JP, Orlichenko LS, Baty CJ, Shiva SS, et al. Lipotoxicity causes multisystem organ failure and exacerbates acute pancreatitis in obesity. Sci Transl Med. 2011;3:107-10.

4. Sporek M, Dumnicka P, Gala-Bladzinska A, Ceranowicz P, Warzecha Z, Dembinski A, et al. Angiopoietin-2 Is an early indicator of acute pancreaticrenal syndrome in patients with acute pancreatitis. Mediators Inflamm. United States.

2016;2016:5780903.

5. Patel K, Trivedi RN, Durgampudi C, Noel P, Cline RA, DeLany JP, et al. Lipolysis of visceral adipocyte triglyceride by pancreatic lipases converts mild acute pancreatitis to severe pancreatitis independent of necrosis and inflammation. Am J Pathol. 2015;185:808-19.

6. Garg PK, Singh VP. Organ failure due to systemic injury in acute pancreatitis. Gastroenterology;United States. 2019;156:2008-23.
7. Tan C, Yang L, Shi F, Hu J, Zhang X, Wang Y, et al. Early systemic inflammatory response syndrome duration predicts infected pancreatic necrosis. J Gastrointest Surg. United States. 2019;24:590-7.

8. Sharma D, Jakkampudi A, Reddy R, Reddy PB, Patil A, Murthy HVV, et al. Association of systemic inflammatory and anti-inflammatory responses with adverse outcomes in acute pancreatitis: preliminary results of an ongoing study. Dig Dis Sci. 2017;62:3468-78 Available from: http://ovidsp.ovid.com/ovidweb.cgi? $\mathrm{T}=\mathrm{JS} \& \mathrm{CSC}=\mathrm{Y} \& N E W S=\mathrm{N} \& \mathrm{PAGE}=$ fulltext $\& \mathrm{D}=$ medl\&AN=29080144. Accessed 5 Sept 2020.

9. Banks PA, Bollen TL, Dervenis C, Gooszen HG, Johnson $C D$, Sarr MG, et al. Classification of acute pancreatitis-2012: revision of the Atlanta classification and definitions by international consensus. Gut. 2013;62:102-11.

10. Sternby H, Bolado F, Canaval-Zuleta HJ, Marra-Lopez C, Hernando-Alonso AI, Del-Val-Antonana A, et al. Determinants of severity in acute pancreatitis: a nationwide multicenter prospective cohort study. Ann Surg. 2018;270(2):348-55

United States. Multicenter study that validated the Revised Atlanta Classification of acute pancreaittis severity.

11. Schepers NJ, Bakker OJ, Besselink MG, Ahmed Ali U, Bollen TL, Gooszen HG, et al. Impact of characteristics 
of organ failure and infected necrosis on mortality in necrotising pancreatitis. Gut. 2018;68(6):gutjnl-2017314657 Available from: http://gut.bmj.com/content/ early/2018/06/27/gutjnl-2017-314657.abstract. Accessed 5 Sept 2020.

Important work that demonstrated that infected necrosis does not impact mortality, and also timing of death among severe pancreatitis patients.

12. Talukdar R, Clemens M, Vege SS. Moderately severe acute pancreatitis: prospective validation of this new subgroup of acute pancreatitis. Pancreas; United States. 2012;41:306-9.

13. Mounzer R, Langmead CJ, Wu BU, Evans AC, Bishehsari F, Muddana V, et al. Comparison of existing clinical scoring systems to predict persistent organ failure in patients with acute pancreatitis. Gastroenterology. United States. 2012;142:1476.

14. Huang Q, Wu Z, Chi C, Wu C, Su L, Zhang Y, et al. Angiopoietin-2 is an early predictor for acute gastrointestinal injury and intestinal barrier dysfunction in patients with acute pancreatitis. Dig Dis Sci. United States; 2020

15. Kibar YI, Albayrak F, Arabul M, Dursun H, Albayrak Y, Ozturk Y. Resistin: new serum marker for predicting severity of acute pancreatitis. J Int Med Res. 2016;44:328-37 Available from: http://ovidsp.ovid. com/ovidweb.cgi? $\mathrm{T}=\mathrm{JS} \& \mathrm{CSC}=\mathrm{Y} \& \mathrm{NEWS}=\mathrm{N} \& \mathrm{PAGE}=$ fulltext $\& D=$ med8\&AN=26857860. Accessed 5 Sept 2020.

16. Samanta J, Singh S, Arora S, Muktesh G, Aggarwal A, Dhaka N, et al. Cytokine profile in prediction of acute lung injury in patients with acute pancreatitis. Pancreatology. Switzerland. 2018;18:878-84.

17.•• van Dijk SM, Hallensleben NDL, van Santvoort HC, Fockens P, van Goor H, Bruno MJ, et al. Acute pancreatitis: recent advances through randomised trials. Gut. 2017;66:2024-32 England.

Excellent summary of recent clinical trials that impacted clinical practice.

18. Vege SS, Gardner TB, Chari ST, Munukuti P, Pearson RK, Clain JE, et al. Low mortality and high morbidity in severe acute pancreatitis without organ failure: a case for revising the Atlanta classification to include "moderately severe acute pancreatitis". Am J Gastroenterol. United States. 2009;104:710-5.

19. Petrov MS, Shanbhag S, Chakraborty M, Phillips ARJ, Windsor JA. Organ failure and infection of pancreatic necrosis as determinants of mortality in patients with acute pancreatitis. Gastroenterology. United States. 2010;139:813-20.

20. Khatua B, El-Kurdi B, Singh VP. Obesity and pancreatitis. Curr Opin Gastroenterol. United States. 2017;33:374-82.

21. Noel P, Patel K, Durgampudi C, Trivedi RN, de Oliveira $\mathrm{C}$, Crowell MD, et al. Peripancreatic fat necrosis worsens acute pancreatitis independent of pancreatic necrosis via unsaturated fatty acids increased in human pancreatic necrosis collections. Gut. 2016;65:100-11 Available from: http://ovidsp.ovid.com/ovidweb.cgi?
$\mathrm{T}=\mathrm{JS} \& \mathrm{CSC}=\mathrm{Y} \& \mathrm{NEWS}=\mathrm{N} \& \mathrm{PAGE}=$ fulltext $\& \mathrm{D}=$ medl\&AN=25500204. Accessed 5 Sept 2020.

22. Bradbury KE, Young HJ, Guo W, Key TJ, Cade JE, Warthon-Medina M, et al. Lipolysis of visceral adipocyte triglyceride by pancreatic lipases converts mild acute pancreatitis to severe pancreatitis independent of necrosis and inflammation. Gastroenterology. 2017;15:100-11

United States. Important work that mechanistically implicates fat lipolysis as mediating process for converting mild to severe pancreatitis.

23. Natu A, Stevens T, Kang L, Yasinow S, Mansoor E, Lopez R, et al. Visceral adiposity predicts severity of acute pancreatitis. Pancreas. 2017;46:776-81.

24. Acharya C, Cline RA, Jaligama D, Noel P, Delany JP, Bae K, et al. Fibrosis reduces severity of acute-onchronic pancreatitis in humans. Gastroenterol Int. 2013;145:466-75 Available from: http://ovidsp.ovid. com/ovidweb.cgi? $\mathrm{T}=\mathrm{JS} \& \mathrm{CSC}=\mathrm{Y} \& \mathrm{NEWS}=\mathrm{N} \& \mathrm{PAGE}=$ fulltext $\& D=$ medl $\& A N=23684709$. Accessed 5 Sept 2020.

25. Huang Z, Ma X, Jia X, Wang R, Liu L, Zhang M, et al. Prevention of severe acute pancreatitis with cyclooxygenase-2 inhibitors: a randomized controlled clinical trial. Am J Gastroenterol. 2020;115:473-80.

26. Roh JS, Sohn DH. Damage-associated molecular patterns in inflammatory diseases. Immune Netw. 2018; 18:e27.

27. Menger MD, Plusczyk T, Vollmar B. Microcirculatory derangements in acute pancreatitis. J Hepato-BiliaryPancreat Surg. 2001;8:187-94 Available from:http:// ovidsp.ovid.com/ovidweb.cgi?T=JS\&CSC=Y\&NEWS= $\mathrm{N} \& P A G E=$ fulltext $\& D=$ med $4 \& A N=11455478$.

Accessed 5 Sept 2020.

28. Ince C, De Backer D, Mayeux PR. Microvascular dysfunction in the critically ill. Crit Care Clin. United States. 2020;36:323-31.

29. Akwii RG, Sajib MS, Zahra FT, Mikelis CM. Role of Angiopoietin-2 in vascular physiology and pathophysiology. Cells. Switzerland. 2019;8:471.

30. Thamm K, Schrimpf C, Retzlaff J, Idowu TO, van Meurs M, Zijlstra JG, et al. Molecular regulation of acute Tie2 suppression in sepsis. Crit Care Med. 2018;46:e92836.

31. Shanbhag ST, Choong B, Petrov M, Delahunt B, Windsor JA, Phillips ARJ. Acute pancreatitis conditioned mesenteric lymph causes cardiac dysfunction in rats independent of hypotension. Surgery. 2018;163(5):1097-105

United States. Novel study that explored a lymph-based mechanism of severe pancreatitis pathophysiology.

32. Khanna AK, Meher S, Prakash S, Tiwary SK, Singh U, Srivastava A, et al. Comparison of Ranson, Glasgow, MOSS, SIRS, BISAP, APACHE-II, CTSI Scores, IL-6, $\mathrm{CRP}$, and procalcitonin in predicting severity, organ failure, pancreatic necrosis, and mortality in acute pancreatitis. HPB Surg. United States. 2013;2013:367581. 
33. Cho JH, Kim TN, Chung HH, Kim KH. Comparison of scoring systems in predicting the severity of acute pancreatitis. World J Gastroenterol. 2015;21:2387-94.

34. Gao W, Yang H-X, Ma C-E. The value of BISAP Score for predicting mortality and severity in acute pancreatitis: a systematic review and meta-analysis. PLoS One. United States. 2015; 10:e0130412.

35. Fei Y, Gao K, Li W-Q. Artificial neural network algorithm model as powerful tool to predict acute lung injury following to severe acute pancreatitis. Pancreatology. Switzerland. 2018;18:892-9.

36. Whitcomb DC, Muddana V, Langmead CJ, Houghton FDJ, Guenther A, Eagon PK, et al. Angiopoietin-2, a regulator of vascular permeability in inflammation, is associated with persistent organ failure in patients with acute pancreatitis from the United States and Germany. Am J Gastroenterol. United States. 2010;105:2287-92.

37. Schaffler A, Hamer O, Dickopf J, Goetz A, Landfried K, Voelk $\mathrm{M}$, et al. Admission resistin levels predict peripancreatic necrosis and clinical severity in acute pancreatitis. Am J Gastroenterol. 2010;105:2474-84 Available from: http://ovidsp.ovid.com/ovidweb.cgi? $\mathrm{T}=\mathrm{JS} \& \mathrm{CSC}=\mathrm{Y} \& N E W S=\mathrm{N} \& \mathrm{PAGE}=$ fulltext $\& \mathrm{D}=$ med6\&AN=20648005. Accessed 5 Sept 2020.

38. Fischer SK, Williams K, Wang L, Capio E, Briman M. Development of an IL-6 point-of-care assay: utility for real-time monitoring and management of cytokine release syndrome and sepsis. Bioanalysis. England. 2019;11:1777-85.

39. Koutroumpakis E, Wu BU, Bakker OJ, Dudekula A, Singh VK, Besselink MG, et al. Admission hematocrit and rise in blood urea nitrogen at $24 \mathrm{~h}$ outperform other laboratory markers in predicting persistent organ failure and pancreatic necrosis in acute pancreatitis: a post hoc analysis of three large prospective databases. Am J Gastroenterol. 2015;110:1707-16.

40. Crockett SD, Wani S, Gardner TB, Falck-Ytter Y, Barkun AN. American Gastroenterological Association Institute guideline on initial management of acute pancreatitis. Gastroenterology. United States.

2018;154:1096-101

41. Fisher JM, Gardner TB. The "golden hours" of management in acute pancreatitis. Am J Gastroenterol. 2012;107:1146-50.

42. Haydock MD, Mittal A, Wilms HR, Phillips A, Petrov MS, Windsor JA. Fluid therapy in acute pancreatitis: anybody's guess. Ann Surg. 2013;257:182-8.

43. Buxbaum JL, Quezada M, Da B, Jani N, Lane C, Mwengela D, et al. Early aggressive hydration hastens clinical improvement in mild acute pancreatitis. Am J Gastroenterol. 2017;112:797-803.

44. Li L, Jin T, Wen S, Shi N, Zhang R, Zhu P, et al. Early rapid fluid therapy is associated with increased rate of noninvasive positive-pressure ventilation in Hemoconcentrated patients with severe acute pancreatitis. Dig Dis Sci. United States. 2020;65(9):2700-11.

45. De Laet IE, Malbrain MLNG, De Waele JJ. A clinician's guide to management of intra-abdominal hypertension and abdominal compartment syndrome in critically ill patients. Crit Care. 2020;24:97.

46. Sakr Y, Birri PNR, Kotfis K, Nanchal R, Shah B, Kluge S, et al. Higher fluid balance increases the risk of death from sepsis: results from a large international audit. Crit Care Med. 2016;45(3):386-94.

47. Bednarczyk JM, Fridfinnson JA, Kumar A, Blanchard L, Rabbani R, Bell D, et al. Incorporating dynamic assessment of fluid responsiveness into goal-directed therapy: a systematic review and meta-analysis. Crit Care Med. 2017;45:1538-45.

48. Wall I, Badalov N, Baradarian R, Iswara K, Li JJ, Tenner $\mathrm{S}$. Decreased mortality in acute pancreatitis related to early aggressive hydration. Pancreas. 2011;40:547-50.

49. Tenner S, Baillie J, DeWitt J, Vege SS, of Gastroenterology AC. American College of Gastroenterology guideline: management of acute pancreatitis. Am J Gastroenterol. 2013;108(15):1416.

50. Li X-Y, He C, Zhu Y, Lu N-H. Role of gut microbiota on intestinal barrier function in acute pancreatitis. World J Gastroenterol. 2020;26:2187-93.

51. Yao H, He C, Deng L, Liao G. Enteral versus parenteral nutrition in critically ill patients with severe pancreatitis: a meta-analysis. Eur J Clin Nutr. England. 2018;72:66-8.

52.• Bakker OJ, van Brunschot S, van Santvoort HC, Besselink MG, Bollen TL, Boermeester MA, et al. Early versus on-demand nasoenteric tube feeding in acute pancreatitis. N Engl J Med. 2014;371:1983-93

This clinical trial demonstrated the lack of benefit of early enteral feeding in comparison to on-demand oral feeding.

53. Vaughn VM, Shuster D, Rogers MAM, Mann J, Conte $\mathrm{ML}$, Saint S, et al. Early versus delayed feeding in patients with acute pancreatitis: a systematic review. Ann Intern Med. United States. 2017;166:883-92.

54. Dutta AK, Goel A, Kirubakaran R, Chacko A, Tharyan P. Nasogastric versus nasojejunal tube feeding for severe acute pancreatitis. Cochrane Database Syst Rev. 2020;3:CD010582.

55. Matta B, Gougol A, Gao X, Reddy N, Talukdar R, Kochhar R, et al. Worldwide variations in demographics, management, and outcomes of acute pancreatitis. Clin Gastroenterol Hepatol Off Clin Pract J Am Gastroenterol Assoc. United States. 2020;18:15671575.e2.

56. Barlass U, Dutta R, Cheema H, George J, Sareen A, Dixit A, et al. Morphine worsens the severity and prevents pancreatic regeneration in mouse models of acute pancreatitis. Gut. 2018;67:600-2 England.

An animal study implicating potential harm of narcotics in acute pancreatitis.

57. Kim J, Tabner AJ, Johnson GD, Brumback BA, Hartzema A. Increased risk of acute pancreatitis with codeine use in patients with a history of cholecystectomy. Dig Dis Sci. United States. 2020;65:292-300.

58. Jabaudon M, Belhadj-Tahar N, Rimmele T, JoannesBoyau O, Bulyez S, Lefrant J-Y, et al. Thoracic epidural analgesia and mortality in acute pancreatitis: a multicenter propensity analysis. Crit Care Med. 
2018;46:e198-205

United States. Extremely intriguing study that demonstrated a possible mortality benefit of epidural analgesia in patients with acute pancreaittis in the intensive care unit.

59. Bulyez S, Pereira B, Caumon E, Imhoff E, Roszyk L, Bernard L, et al. Epidural analgesia in critically ill patients with acute pancreatitis: the multicentre randomised controlled EPIPAN study protocol. BMJ Open. England. 2017;7:e015280.

60. Schepers NJ, Hallensleben NDL, Besselink MG, Anten M-PGF, Bollen TL, da Costa DW, et al. Urgent endoscopic retrograde cholangiopancreatography with sphincterotomy versus conservative treatment in predicted severe acute gallstone pancreatitis (APEC): a multicentre randomised controlled trial. Lancet (London, England). England. 2020;396:167-76.

61. Trikudanathan G, Vege SS. Current concepts of the role of abdominal compartment syndrome in acute pancreatitis - an opportunity or merely an epiphenomenon. Pancreatology. 2014;14:238-43 Available from: http://ovidsp.ovid.com/ovidweb.cgi?T=JS\&CSC=
Y\&NEWS $=$ N\&PAGE $=$ fulltext $\& D=$ med $8 \& A N=$ 25062870. Accessed 5 Sept 2020.

62. Marcos-Neira P, Zubia-Olaskoaga F, Lopez-Cuenca S, Bordeje-Laguna L. Relationship between intraabdominal hypertension, outcome and the revised Atlanta and determinant-based classifications in acute pancreatitis. BJS Open. England. 2017;1:175-81.

63.• van Brunschot $S$, van Grinsven J, van Santvoort HC, Bakker OJ, Besselink MG, Boermeester MA, et al. Endoscopic or surgical step-up approach for infected necrotising pancreatitis: a multicentre randomised trial. Lancet. (London, England). 2018;391:51-8.

\section{Publisher's Note}

Springer Nature remains neutral with regard to jurisdictional claims in published maps and institutional affiliations. 